\title{
Study of Key Stakeholders for their Knowledge, Attitude \& Practice on Adverse Drug Reaction Reporting in Tertiary Care Hospitals in Jaipur, India
}

\author{
Rahul Sharma*
}

${ }^{1}$ Assistant Professor, IIHMR University, Jaipur, Rajasthan, India

Received: April 22, 2017; Accepted: May 30, 2017; Published: June 20, 2017

*Corresponding author: Rahul Sharma, Assistant Professor, IIHMR University, Jaipur, India. Tel no: +91 80588 29298; Email: rahulsharma1in@gmail. com

\section{Abstract}

Adverse Drug Reactions (ADR) is the leading cause for the hospital administration, morbidity, and mortality as per the established data. Present pharmacovigilance program of India is performing well for strengthening ADR reporting system. The current project is aimed to study knowledge, attitude and practices of health care professionals and key stakeholders for Adverse Drug reaction reporting of marketed medicines.

The study was conducted in four major tertiary care hospitals in Jaipur from Government and private sector from May to July 2015. The data was collected from key stakeholders with a sample size of 1022 (male \& female of age group 18-70 years) using a semi structured questionnaire tool separate for different segment of the key stakeholders. Data was cleaned, and analysed for its descriptive report and assessment of the situation.

There is less aware of the Adverse Drug reaction reporting system, only $32 \%$ of the doctor \'s sample is aware about the reporting system of Adverse Drug reaction in India as well as the mandatory time period in case of serious Adverse Drug reaction reporting (26\%). The location for regional office for Adverse Drug reaction reporting is known to only $26 \%$ of the sampled Doctors in all the major four tertiary care hospitals of Jaipur. It is found that the awareness about $\backslash$ 'To whom Adverse Drug reaction should be reported $\backslash$ ' is seen in only $12 \%$ of the sample Doctors. While only $6 \%$ of them are provided any training about the Adverse Drug reaction reporting procedure. It was found that only $57 \%$ of the sampled doctors had encountered patients with Adverse Drug reaction in their clinical practice during last one year of the study, and only $45 \%$ of them are recording Adverse Drug reactions in their record book or file.

It was found that although the health professionals are aware of the basic knowledge about the Adverse Drug reaction due involvement of key terms in their basic education and training but there is a huge gap found in knowledge parameter as seen in unawareness about the reporting system of Pharmacovigilance.

\section{Introduction}

India is the second most populous country in the world, with over 1.2 billion people (July 2015), i.e. more than a sixth of the world's population; India also carries a huge disease burden among its population. There are between $60,000-80,000$ brands of drugs available in the Indian market that are irrationally prescribed and misused [1].

An adverse drug reaction can be defined as "an appreciably harmful or unpleasant reaction, resulting from an intervention related to the use of a medicinal product, which predicts hazard from future administration and warrants prevention or specific treatment, or alteration of the dosage regimen, or withdrawal of the product." Such reactions are currently reported by use of WHO's Adverse Reaction Terminology, which will eventually become a subset of the International Classification of Diseases. Adverse drug reactions are classified into six types (with mnemonics): dose-related (Augmented), non-dose-related (Bizarre), dose-related and timerelated (Chronic), time-related (Delayed), withdrawal (End of use), and failure of therapy (Failure) [2]. Adverse Drug Reactions contribute to a significant number of morbidity and mortality all over the world. Adverse Drug Reaction can be seen in clinical practice with both new as well as marketed medicines [3].

The Adverse Drug Reaction reporting can be either voluntary or obligatory as per WHO (ICH) guidelines, but such process is not followed properly in practice keeping in view the low number of reporting in developing and underdeveloped nations [3]. Spontaneous reporting of Adverse Drug Reaction is commonly practiced method for monitoring of Adverse Drug Reaction. Healthcare practitioners have an important role in Pharmacovigilance and Adverse drug reactions (ADR) reporting.

The Pharmaceutical industry in India is valued at Rs. 90,000 Crore and is growing at the rate of $12-14 \%$ per annum. Exports are growing at $25 \%$ Compound Annual Growth Rate (CAGR) every year. The total export of Pharma products is to the 
extent of Rs. 40,000 Crore. India is now being recognized as the 'Global pharmacy of Generic Drugs' \& has distinction of providing generic quality drugs at affordable cost. India is also emerging rapidly as a hub of Global Clinical trials \& a destination for Drug Discovery \& Development [4].

Pharmacovigilance (PV) is and the sum of activities related to the detection, assessment, understanding, and prevention of Adverse Drug Reactions caused by drugs. Spontaneous reporting of suspected Adverse Drug Reactions to PV centres is of utmost importance to generate the safety data of marketed drugs. Indeed, understanding the importance of reporting Adverse Drug Reactions, national and international organizations urged health professionals to prioritize Adverse Drug Reaction reporting in order to curtail Adverse Drug Reaction related problems. In India, the national Pharmacovigilance Programme of India (PvPI) was established by the Central Drugs Standard Control Organization (CDSCO) in 2004 to monitor Adverse Drug Reactions and to provide drug safety reports to the WHO-Adverse Drug Reaction monitoring centre in Uppsala, Sweden.

Recent published data suggest the less number of Adverse Drug Reaction cases reported by various PV centres in major cities compared to rest of the world (Indian Pharmacopoeia Commission report, 2014) [5]. Which indicate low awareness, knowledge, and inadequate practice of Adverse Drug Reaction reporting is the region.

There is three times the number of people killed by automobiles and is the fourth leading cause of death in the United States [6]. The current prevailing incidence of serious Adverse Drug Reactions is $6.7 \%$ in India [7]. Only heart disease, cancer and stroke kill more people than adverse reactions to drugs. This staggering figure does not include drugs administered in error, nor those taken as a suicidal intent [8]. Adverse Drug Reactions (ADRs) constitute a significant health problem with consequences for the patient as well as for society. Suspected Adverse Drug Reactions have been reported to occur in about 2-14\% of hospitalized patients. In about 5\% of deceased hospitalized patients suspected Adverse Drug Reactions may have caused or contributed to the fatal outcome [6].

Spontaneous or voluntary reporting of suspected Adverse Drug Reactions is one of the vital roles of all health professionals. In India, under-reporting of Adverse Drug Reactions by health professionals is recognized as one of the leading causes of poor Adverse Drug Reaction signal detection. The misuse and faulty prescribing account for considerable development of Adverse Drug Reactions (ADRs) that are one of the major causes of mortality and morbidity, unplanned hospitalization, and increased healthcare cost, worldwide. Thus, early identification of Adverse Drug Reactions is extremely important for both government and non-government health care organizations.

Drug Controller General of India (DCGI) and Indian Council of Medical Research (ICMR) have established many peripheral PV centres in various hospitals located in major Indian cities, to coordinate Adverse Drug Reaction monitoring throughout India [9]. The aim of creating different centre is to increase awareness \& reach in the population for spontaneous reporting. The low number of Adverse Drug Reactions being reported is able to produce the data with less significance. India reported no more than $2 \%$ of globally occurring Adverse Drug Reactions (ADRs) [10].

As per the Scenario for Number of ADR had been reported in India during last few years 27867 (in year 2013), 40810 (in year 2014) \& 50450 (in year 2015) there is nearly $10 \%$ increase in the adverse drug reactions despite the growth in population is $1.2 \%$. The difference in the growth of the population with respect to adverse drug reaction can be considered with increase in awareness level of the stakeholders and the expansion of the Pharmacovigilance Program of India [11].

\section{Requirement of Adverse Drug Reaction monitoring}

Reason to monitor the adverse reactions to drugs, if their safety profiles have already been studied adequately before their commercial release is, to assess the medicine safety in the population rather than sampled with variable variables like environmental, health, food, gene pool etc.

Drug monitoring for Adverse Drug Reactions make the drugs safer, as per the general perception, safety is something that is inherent in the physiochemical properties of the drug molecule \& has to be monitored for its varied effects under different exposures.

The formal therapeutic trials are conducted in carefully controlled conditions; in highly selected and limited number of patients, so that the exact safety profile of the drug in the real life situations is not known. Moreover, prior to its release, a drug is studied in just limited cases. Therefore, adverse reactions having frequency less than 0.5 to $1 \%$ are missed. Children, pregnant women, and elderly are not included in clinical trials for ethical reasons. Therefore, the safety of the drug in these cases remains unknown until its release.

Another important drawback of clinical trials is that they can only report adverse reactions that appear within the finite duration of trial. Delayed reactions would be missed.

Reporting of adverse drug reactions is done by mainly two methods: spontaneous and intensive. Though plagued by numerous problems like low yield of reports, sub-optimal quality and imperfect nature, these have often served to be a useful source of data or provided early warning signals for the drug related regulatory actions.

The study was conducted to assess the need of implementing a system for the gathering the Adverse Drug Reaction (ADR) report for the medicines after their use. The key stakeholders involved in the Adverse Drug Reaction \& medicine usage are Doctors, Pharmacists, Nurses and Patients. The study is used to describe the knowledge, attitude and practice for the Adverse Drug Reaction reporting in their practicing hospitals so as to establish a relation between the KAP and the Adverse Drug Reaction reporting as in practice in India. 
The study thus collected evidence useful for the top managers as well as policy makers to strengthen upon the gap which can be found beneficiary for the population using that medicine.

Objective of the study: The study was intended to be done in local environment with the involvement of key stakeholders i.e. Doctor, Pharmacist, Nurse and Patient. The objectives of the study are:

a.To study knowledge, attitude and practices of health care professionals and key stakeholders for Adverse Drug Reaction reporting of marketed drugs;

b.To identify current gap in knowledge and practices related to Adverse Drug Reaction reporting of marketed drugs.

c.To suggest upon possible solutions for the problem found.

\section{Methodology}

A Descriptive study was conducted in the tertiary care Hospitals in Jaipur, Rajasthan, India and consists of Target respondents Drug Prescribers (Doctors), Pharmacist, Nurses and Patients for the study (either sex). Sampling and Sample Size: A total of four tertiary care hospitals including private and public hospitals \& teaching, non-teaching hospital are covered under the project.

Total key stakeholders involved in the study are 1022 details for the sample distribution is provided as: Doctors (306), Nurses (337), Pharmacists (37) \& Patients (342) are involved in the study.

Sample calculation is based upon the total number of departments \& personals working in the hospital and their statistical significant count (Minimum $10 \%$ in case of large number of availability like for patients and maximum $50 \%$ in case of less number of availability like for Pharmacists).

Data collection for the doctors is done by professional experienced person who is able to converse with the doctors, hence the professional qualified field investigator were used for the project

The methods of data collection includes-

-Review of formats, reports and records: A review of the record \& reports available for the current Adverse Drug Reaction reporting and the methods used to check upon Adverse Drug Reaction related issues are studied.

\section{-Interview with:}

-Drug Prescribers (Doctors): Being the important stakeholder, the doctors are interviewed for understanding their knowledge and practice for the adverse drug reaction reporting $\&$ issues.

-Pharmacist: They deal with all types of drugs \& provide important information to deal with the issues related to the Adverse Drug Reaction.
-Nurses: The problems with in in-patients are described in detail by nursing staff.

-Exit Interview with Patients: The consequences of Adverse Drug Reaction is suffered by patients, hence, they are included in the study to understand their issues \& problems.

Tools used for the data collection are: Interview schedule, Exit Interview schedule \& Informed consent form.

\section{Operational Plan}

The data collection tools are developed in English and later on translated in to Hindi (local language). A back translation into English is also done for quality check.

Recruitment of the Field Investigators is done by HR department, followed by their one day training. The training included the basic knowledge about Pharmacovigilance system in India, Adverse Drug Reaction and understanding about tools along with the project. The tools are pre-tested in a hospital other than sampled hospital with the team members of field investigators. The final tools are peer-reviewed.

The proposal \& tools are submitted to the Institutional ethics Review Board for their approval. After adhering with the changes in the tools \& Informed consent form made by the ethical review board the tools are finalized for the study. Hospital permission was sought from the various hospitals, only the hospitals which provide with the permission had been involved in the study.

On the basis of approval and controlling confounders following four hospitals are involved in the study. Pre testing of the tools are done in Hospital other than sampled. Visits in the sampled hospital is done by Principle Investigator with the team members to meet with the Hospital in-charge and initiation of the data collection process followed by data collection process.

The surveillance of the team members is done by using regular back check, spot check by principle investigator \& also to check upon the data quality. The filled tools are screened for errors \& submitted back to principle investigator. The review of the filled tools are done by principle investigator and digitized by data entry operator at IIHMR University campus.

\section{Data management}

The filled tools \& digitized data collected from the field was securely stored by principle investigator. All the identifiers are removed and the transcripts are coded to ensure the confidentiality of data.

The data cleaning, acceptance of only data which is in good quality was involved in assessment. Partial \& incomplete data was rejected. Screening of the data was done to check the data quality. Data entry was done in Microsoft Excel (2007) followed by Cleaning of data. Analysis of the data for descriptive statistics and variability of the data gathered is done using statistical software SPSS (version 16). 


\section{Result and Discussion}

The highest number of sample is collected from Jaipuria Hospital, while the Fortis hospital consists of only $10 \%$ of the sample size for the reason of the size of the hospital (number of respondents present in the context), SMS hospital is the biggest hospital present but due to the busy schedule of the Doctors a minimum required sample can be drawn from there. The situation of the sample size is similar in the other categories of representatives i.e. Nurses, Pharmacist \& Patients.

The distribution of the sample is based upon the sample size calculation consisting of a minimum of $10 \%$. The sample consisting of the uneven distribution of the male \& females. The Doctors consisting of the $65-80 \%$ males \& $20-35 \%$ females, while the Nurse sample consists of $29-44 \%$ male only. Pharmacists are majorly dominated by the males (83-100\%). Patient sample consist of $59-74 \%$ male randomly in all hospitals.

The mean age of the doctor's sample is 36.4 year (SD 7.3), Nurse is 27.7 year (SD 5.7), Pharmacist is 31.7 year (SD 7.9), \& Patient is 32 year (SD 9.3). The major sample size of doctors in 36-40 year range is from Jaipuria \& M.G. Hospital. The nursing population is majorly consisting of less the 30 year in all the sampled hospitals. There is low availability of sample more than 36 year in all hospitals except SMS hospital. A major group among the Pharmacist is from the age category of 26-30 year. The sample group of more than 40 year is not found to be present in all hospitals except Jaipuria Hospital. There are more patient population in the age range of below 30 years, while there are less number of respondents relatively in age over 31 year.

It was found that the majority of doctors are having post graduate qualification \& post graduate with added specialization. The sample selected is consisting of very low number of doctors with only medical graduate qualification or graduate with added specialization.

The majority of the doctors found in the sample were having experience of 2-10 years. While the doctors found with lower or higher range are very low in number.

\section{Doctor's Knowledge}

It is observed that the all of the sample of doctors are aware about the term Adverse Drug Reaction with knowledge of definition of Adverse Drug Reaction (98\%) from the reference of their study in undergraduate or Post graduate course. Although the entire sampled Doctor's population (100\%) is said to prac- tice the Adverse Drug Reaction reporting regularly, but they are less aware of the Adverse Drug Reaction reporting system, only $32 \%$ of the doctor's sample is aware about the reporting system of Adverse Drug Reaction in India as well as the mandatory time period in case of serious Adverse Drug Reaction reporting (26\%). The location for regional office for Adverse Drug Reaction reporting is known to only $26 \%$ of the sampled Doctors in all the major four tertiary care hospitals of Jaipur.

About half (54\%) of the Doctor's perceive that the Adverse Drug Reaction reporting creates an additional work load to them but it felt as a part of duty of health professionals (99\%) and reporting is important to get aware about the drug safety (99\%). The general perception is that the Adverse Drug Reaction reporting is beneficiary for the patient (99\%) and is important for the health care system (100\%).

Before reporting about the Adverse Drug Reaction, there is a need to be sure that it is related to the drug only then the reporting should be performed (93\%). The Adverse Drug Reaction which needed to be reported are only for the prescribed medicines (46\%), Adverse Drug Reaction related with non-prescribed drugs need not to be reported (25\%). Doctors are not convinced to the statement that Adverse Drug Reaction which causes persistent disability should be reported (66\% disagree).

\section{Doctor's Awareness}

It is found that the awareness about 'To whom Adverse Drug Reaction should be reported' is seen in only $12 \%$ of the sample Doctors. While only $6 \%$ of them are provided any training about the Adverse Drug Reaction reporting procedure.

\section{Doctor's Practice}

It was found that only $57 \%$ of the sampled doctors had encountered patients with Adverse Drug Reaction in their clinical practice during last one year of the study, and only $45 \%$ of them are recording Adverse Drug Reactions in their record book or file. Even if they are claiming to report Adverse Drug Reaction regularly $79 \%$ and claiming to advice patient for possible drugdrug-food interaction in their daily routine $(100 \%)$ but neither had they undergone any training related to Adverse Drug Reaction reporting (93\%) nor they have got any Adverse Drug Reaction reporting form available in their organization (70\%). Nearly half of the doctors accepted that the Adverse Drug Reactions are well documented in the medicine's leaflets (56\%) (Table 1).

Table 1: Doctor's Knowledge, awareness \& Practice for the adverse drug reaction reporting

\begin{tabular}{|c|c|c|}
\hline \multicolumn{2}{|c|}{ Doctor's Knowledge } & \multirow{2}{*}{$\begin{array}{c}\text { Response (\%) } \\
99.7\end{array}$} \\
\hline 101 & Have you heard the term Adverse Drug Reaction (ADR)? & \\
\hline 102 & Define Adverse Drug Reaction & 98 \\
\hline 103 & Have you heard about Adverse Drug Reaction reporting system in India? & 32.4 \\
\hline 126 & $\begin{array}{l}\text { Do you know about mandatory time period in case of serious Adverse } \\
\text { Drug Reaction reporting? }\end{array}$ & 26.2 \\
\hline 127 & Where Regional office for reporting Adverse Drug Reaction is located? & 25.5 \\
\hline
\end{tabular}




\begin{tabular}{|c|c|c|}
\hline 111 & Adverse Drug Reaction reporting to be practiced regularly? & 100 \\
\hline 112 & Reporting creates additional work load? & 53.9 \\
\hline 113 & Reporting Adverse Drug Reaction is part of duty of Health professionals? & 98.7 \\
\hline 114 & Reporting about 'drug safety' is important? & 99 \\
\hline 115 & Reporting is beneficial to the patient? & 99 \\
\hline 116 & Reporting drug safety is important for the health care system? & 99.7 \\
\hline 117 & $\begin{array}{l}\text { There is a need to be sure, that specific Adverse Drug Reaction is related } \\
\text { to a drug, before reporting? }\end{array}$ & 93.1 \\
\hline 118 & $\begin{array}{l}\text { Only Adverse Drug Reaction of doctors prescribed drugs need to be } \\
\text { reported? }\end{array}$ & 45.9 \\
\hline 119 & $\begin{array}{l}\text { Adverse Drug Reaction related with non-prescribed drugs need not to be } \\
\text { reported? }\end{array}$ & 25.3 \\
\hline 120 & $\begin{array}{l}\text { Only Adverse Drug Reaction that cause persistent disability should be } \\
\text { reported? }\end{array}$ & 34.3 \\
\hline \multicolumn{3}{|c|}{ Doctor's Awareness } \\
\hline 107 & To whom Adverse Drug Reactions should be reported? & 12.4 \\
\hline 125 & Where the training held? & 6.2 \\
\hline \multicolumn{3}{|c|}{ Doctor's Practice } \\
\hline 104 & $\begin{array}{l}\text { Have you ever encountered patient with Adverse Drug Reaction in your } \\
\text { clinical practice, in the last } 12 \text { months? }\end{array}$ & 57.3 \\
\hline 105 & Do you record the Adverse Drug Reactions encountered in your practice? & 44.9 \\
\hline 106 & How often you report any Adverse Drug Reactions in your practice? & 79.4 \\
\hline 108 & $\begin{array}{l}\text { How often do you give advice to your patients on possible drug- drug or } \\
\text { drug- food interactions in your daily routine? }\end{array}$ & 99.7 \\
\hline 121 & Adverse Drug Reaction reporting form available in your organization? & 30.2 \\
\hline 122 & $\begin{array}{l}\text { Adverse Drug Reactions of marketed drugs are well documented by } \\
\text { Pharmaceutical companies in their 'Patient information leaflet'? }\end{array}$ & 55.7 \\
\hline 123 & $\begin{array}{l}\text { Have you had undergone any workshop or training specifically related to } \\
\text { Adverse Drug Reaction reporting? }\end{array}$ & 7.3 \\
\hline
\end{tabular}

\section{Nurses Knowledge}

Although the term Adverse Drug Reaction is known by majority of the sampled Nurses (97\%) but only $80 \%$ are aware about the definition of Adverse Drug Reaction. The reporting system of Adverse Drug Reaction is known by only $14 \%$ of the sample in four major tertiary care hospitals. When the sample was asked about the mandatory time period for serious Adverse Drug Reactions only $27 \%$ of the sample was able to provide right answer. The situation was critical in the sampled population for the knowledge about the regional office for Adverse Drug Reaction reporting only $2 \%$ of them are known to its location.

\section{Nurses Awareness}

Although all the sampled nurses are sure about necessity of Adverse Drug Reaction reporting regularly (100\%), it is a general assumption that Adverse Drug Reaction reporting is part of the duty of Health professionals (100\%) and is essentially required for knowing about the safety of the medicine (100\%), which is important in the health care system (99\%). There is needed to be sure that the Adverse Drug Reaction is related with the specific medicine before reporting (90\%). But it is strongly perceived that the only Adverse Drug Reaction of the doctors prescribed medicines are needed to be reported (100\%) while non-prescribed medicines are needed not to be reported (38\%). About half of the sample agrees upon the term that 'Only Adverse Drug Reaction which causes persistent disability should be reported' (49\%). There is a general belief in majority of the sample that Adverse Drug Reaction reporting is part of the health care system \& it improves quality of patient care (97\%). Majority of the sample disagree $(73 \%)$ upon the statement that 'one report make no difference'. The usefulness of the Adverse Drug Reaction reporting system is felt by $82 \%$ of the sample while $44 \%$ agree upon the addition workload added by enforcing Adverse Drug Reaction reporting system. Majority of the sample (76\%) agree upon the efficiency of the Adverse Drug Reaction reporting by designated person in their organization while they are majorly unaware $(88 \%)$ about to whom Adverse Drug Reactions should be reported.

\section{Nurses Practice}

It was found that only $34 \%$ of the sample Nurses had encountered patients with Adverse Drug Reaction in their clinical practice with in last one year of the study they are less in practice of recording the Adverse Drug Reaction (39\%). Although they are 


\begin{tabular}{|c|c|c|}
\hline \multicolumn{2}{|c|}{ Nurses Knowledge } & \multirow{2}{*}{$\begin{array}{c}\text { Response or Right response (in \%) } \\
97.3\end{array}$} \\
\hline 101 & Have you heard the term Adverse Drug Reaction & \\
\hline 102 & Define Adverse Drug Reaction & 80.3 \\
\hline 103 & $\begin{array}{l}\text { Have you heard about Adverse Drug Reaction reporting system } \\
\text { in India? }\end{array}$ & 13.8 \\
\hline 129 & $\begin{array}{l}\text { Know about mandatory time period in case of serious Adverse } \\
\text { Drug Reaction reporting }\end{array}$ & 26.8 \\
\hline 130 & $\begin{array}{l}\text { Location of Regional office for reporting Adverse Drug } \\
\text { Reaction }\end{array}$ & 2.1 \\
\hline \multicolumn{2}{|c|}{ Nurses Awareness } & \\
\hline 111 & Adverse Drug Reaction reporting to be practiced regularly & 99.7 \\
\hline 112 & $\begin{array}{l}\text { Reporting Adverse Drug Reaction is part of duty of Health } \\
\text { professional }\end{array}$ & 97.9 \\
\hline 113 & Reporting about 'drug safety' is important & 99.7 \\
\hline 114 & $\begin{array}{l}\text { Reporting drug safety is important for the health care system } \\
\mathrm{n}=336\end{array}$ & 98.8 \\
\hline 115 & $\begin{array}{l}\text { There is a need to be sure that Adverse Drug Reaction is } \\
\text { related to the drug before reporting }\end{array}$ & 90.2 \\
\hline 116 & $\begin{array}{l}\text { Only Adverse Drug Reaction of doctors prescribed drugs need } \\
\text { to be reported? }\end{array}$ & 99.7 \\
\hline 117 & $\begin{array}{l}\text { Adverse Drug Reaction related with non-prescribed drugs } \\
\text { need not to be reported }\end{array}$ & 38 \\
\hline 118 & $\begin{array}{l}\text { Only Adverse Drug Reaction that cause persistent disability } \\
\text { should be reported }\end{array}$ & 49.2 \\
\hline 119 & Reporting Adverse Drug Reaction is part of health care & 97 \\
\hline 120 & $\begin{array}{l}\text { Reporting Adverse Drug Reactions improves quality of patient } \\
\text { care }\end{array}$ & 97.4 \\
\hline 121 & One report of Adverse Drug Reaction makes no difference & 27.5 \\
\hline 122 & Reporting is not useful to the patient & 17.8 \\
\hline 123 & Reporting creates additional work load & 44.4 \\
\hline 132 & $\begin{array}{l}\text { Do you think the above responsible person is reporting } \\
\text { efficiently? }\end{array}$ & 76.3 \\
\hline 107 & To whom Adverse Drug Reactions should be reported? & 12.2 \\
\hline \multicolumn{2}{|c|}{ Nurses Practice } & \\
\hline 104 & $\begin{array}{l}\text { Have you ever encountered patient with Adverse Drug } \\
\text { Reaction in your clinical practice, in the last } 12 \text { months? }\end{array}$ & 34 \\
\hline 105 & $\begin{array}{l}\text { Do you record the Adverse Drug Reactions encountered in } \\
\text { your practice? }\end{array}$ & 39 \\
\hline 106 & How often you report any Adverse Drug Reactions? & 82.8 \\
\hline 108 & $\begin{array}{l}\text { How often do you give advice to your patients on possible } \\
\text { drug- drug or drug- food interactions (Result in \%) }\end{array}$ & 95.8 \\
\hline 124 & $\begin{array}{l}\text { Is the Adverse Drug Reaction reporting form available in your } \\
\text { organization? }\end{array}$ & 28.2 \\
\hline 125 & $\begin{array}{l}\text { Is Adverse Drug Reactions of marketed drugs are well } \\
\text { documented by Pharmaceutical companies in their 'Patient } \\
\text { information leaflet'? }\end{array}$ & 66.4 \\
\hline 126 & $\begin{array}{l}\text { Have you had undergone any workshop or training specifically } \\
\text { related to Adverse Drug Reaction reporting? }\end{array}$ & 12.3 \\
\hline 129 & $\begin{array}{l}\text { Do you know about mandatory time period in case of serious } \\
\text { Adverse Drug Reaction reporting? }\end{array}$ & 26.8 \\
\hline
\end{tabular}


reporting the Adverse Drug Reactions (83\%) \& advising the patient on possible drug-drug-food interaction (96\%) but they are less aware of the mandatory time period for serious Adverse Drug Reaction reporting (27\%) as they had majorly not undergone any training for the same (only $12 \%$ had training). It was found that only $28 \%$ are aware of the Adverse Drug Reaction reporting form availability in their organization. The sampled Nursing staffs majorly agree upon term that Adverse Drug Reactions of marketed drugs are well documented by Pharmaceutical companies in their 'Patient information leaflet' (66\%) (Table 2).

\section{Pharmacist's Knowledge}

It was found that the $92 \%$ of the sample had heard about the term Adverse Drug Reaction. The definition of Adverse Drug Reaction is known in $81 \%$ of the sampled Pharmacist which is similar to the Nurses. The reporting system for Adverse Drug Reaction is known to $41 \%$ of the sample in this category while the reporting time period for the serious Adverse Drug Reaction is known to only $40 \%$ of the sampled Pharmacists.

\section{Pharmacist's Awareness}

There is a general belief that the Adverse Drug Reaction reporting is to be practiced regularly (97\%) and it part if duty of Health professional (97\%). All of the sampled population of the Pharmacists agree upon the term that medicine safety is important (100\%) \& needed in health care system (97\%), but there is a need to be sure that Adverse Drug Reaction is related to the drug before reporting (94\%). Nearly half (49\%) of the sampled population is sure that the only Adverse Drug Reaction related to prescribe medicines are needed to be reported while on the contrary $61 \%$ sample agree upon the need of reporting for nonprescribed medicines, only $35 \%$ of the sample is disagree for the statement "Only Adverse Drug Reaction that cause persistent disability should be reported". Reporting Adverse Drug Reaction is part of the health care system (97\%) and it improves quality it patient care (97\%). Majority of the sample is disagreed upon the statement that 'One report of Adverse Drug Reaction makes no difference' (68\%) while agree upon the usefulness of the Adverse Drug Reaction reporting to the patients (84\%). About one third $(32 \%)$ of the sample agree upon the additional work load by Adverse Drug Reaction reporting, a major proportion (75\%) believe that the designated person for reporting Adverse Drug Reaction is working efficiently while they are majorly unaware (63\%) about to whom Adverse Drug Reactions should be reported.

\section{Pharmacist's Practice}

Similar to the Nurses Pharmacists also had encountered only 39\% of the patients with Adverse Drug Reaction in last one year of the study; they are also very recording of the Adverse Drug Reactions (13\%). Although they are majorly reporting $(63 \%)$ the Adverse Drug Reaction and advices patient on possible drug-drug-food interactions (87\%). As per the sampled pharmacists there is low awareness about Adverse Drug Reaction reporting form availability in their organization (31\%). Nearly half of the Pharmacists agree upon the term that the Adverse Drug Reactions of marketed drugs are well documented by Pharmaceutical companies in their 'Patient information leaflet' (53\%). Only 31\% of the sampled population in the group had undergone any training or workshop related to the Adverse Drug Reaction reporting (Table 3).

\begin{tabular}{|c|c|c|}
\hline \multicolumn{2}{|c|}{ Pharmacist's Knowledge } & \multirow{2}{*}{$\begin{array}{c}\text { Response (\%) } \\
91.9\end{array}$} \\
\hline 101 & Have you heard the term Adverse Drug Reaction? & \\
\hline 102 & Define Adverse Drug Reaction & 81.1 \\
\hline 103 & $\begin{array}{l}\text { Have you heard about Adverse Drug Reaction reporting system } \\
\text { in India? }\end{array}$ & 40.5 \\
\hline 129 & $\begin{array}{l}\text { Do you know about mandatory time period in case of serious } \\
\text { Adverse Drug Reaction reporting? }\end{array}$ & 40 \\
\hline \multicolumn{3}{|c|}{ Pharmacist's Awareness } \\
\hline 111 & Adverse Drug Reaction reporting to be practiced regularly & 97.3 \\
\hline 112 & $\begin{array}{l}\text { Reporting Adverse Drug Reaction is part of duty of Health } \\
\text { professional }\end{array}$ & 97.3 \\
\hline 113 & Reporting about 'drug safety' is important & 100 \\
\hline 114 & Reporting drug safety is important for the health care system & 97.3 \\
\hline 115 & $\begin{array}{l}\text { There is a need to be sure that Adverse Drug Reaction is related } \\
\text { to the drug before reporting }\end{array}$ & 94.5 \\
\hline 116 & $\begin{array}{l}\text { Only Adverse Drug Reaction of doctors prescribed drugs need } \\
\text { to be reported? }\end{array}$ & 48.6 \\
\hline 117 & $\begin{array}{l}\text { Adverse Drug Reaction related with non-prescribed drugs need } \\
\text { not to be reported }\end{array}$ & 40.5 \\
\hline 118 & $\begin{array}{l}\text { Only Adverse Drug Reaction that cause persistent disability } \\
\text { should be reported }\end{array}$ & 64.8 \\
\hline
\end{tabular}




\begin{tabular}{|c|c|c|}
\hline 119 & Reporting Adverse Drug Reaction is part of health care & 97.3 \\
\hline 120 & $\begin{array}{l}\text { Reporting Adverse Drug Reactions improves quality of patient } \\
\text { care }\end{array}$ & 97.2 \\
\hline 121 & One report of Adverse Drug Reaction makes no difference & 32.4 \\
\hline 122 & Reporting is not useful to the patient & 16.2 \\
\hline 123 & Reporting creates additional work load & 32.4 \\
\hline 107 & To whom Adverse Drug Reactions should be reported? & 37.1 \\
\hline 132 & $\begin{array}{l}\text { Do you think the above responsible person is reporting } \\
\text { efficiently? }\end{array}$ & 75 \\
\hline \multicolumn{3}{|c|}{ Pharmacist's Practice } \\
\hline 104 & $\begin{array}{l}\text { Have you ever encountered patient with Adverse Drug Reaction } \\
\text { in your clinical practice, in the last } 12 \text { months }\end{array}$ & 38.9 \\
\hline 105 & $\begin{array}{l}\text { Do you record the Adverse Drug Reactions encountered in your } \\
\text { practice? }\end{array}$ & 12.5 \\
\hline 106 & How often you report any Adverse Drug Reactions? & 62.5 \\
\hline 108 & $\begin{array}{l}\text { How often in daily practice, do you give advice to your patients } \\
\text { on possible drug- drug or drug- food interactions? }\end{array}$ & 86.5 \\
\hline 124 & $\begin{array}{l}\text { Is the Adverse Drug Reaction reporting form available in your } \\
\text { organization? }\end{array}$ & 30.6 \\
\hline 125 & $\begin{array}{l}\text { Is Adverse Drug Reactions of marketed drugs are well } \\
\text { documented by Pharmaceutical companies in their 'Patient } \\
\text { information leaflet'? }\end{array}$ & 52.8 \\
\hline 126 & $\begin{array}{l}\text { Have you had undergone any workshop or training specifically } \\
\text { related to Adverse Drug Reaction reporting? }\end{array}$ & 30.8 \\
\hline
\end{tabular}

\section{Patient's Knowledge}

The patients are less known to the term adverse drug reaction (52\%) but the common alternative term for it they refer is side effect which is known to $94 \%$ of the sampled population. The Patients are also able to define the term (60\%) adverse drug reaction. Patients are majorly in favour of reporting of Adverse Drug Reaction (97\%).

\section{Patient's Awareness}

There is in general acceptance (95\%) upon the requirement of awareness for patients regarding Adverse Drug Reaction reporting. Almost all of the sampled Patients agree upon the term 'reporting Adverse Drug Reaction is part of duty of health professional' (97\%) and improves quality of patient care (99\%) while $90 \%$ of the sample agree upon the fact that there is a need to confirm that Adverse Drug Reaction is related to the medicine, before reporting. Only Adverse Drug Reaction of doctor prescribed medicines are needed to be reported is agreed by $58 \%$ of the sample while there is a general majorly disagree (64\%) upon the term of not reporting any Adverse Drug Reaction related with non- prescribed medicines. There is a low awareness among patients, for reporting only Adverse Drug Reaction which cause persistent disability (62\%). Majority of the sample is disagree (61\%) upon the term that 'One report of Adverse Drug Reaction makes no difference' and also disagree (76\%) upon 'Reporting is not useful for patients'. Almost all Patents are willing to report in case encounter an Adverse Drug Reaction (97\%) although they do not know majorly that, Adverse Drug Reaction can be reported (64\%) and also about availability of Adverse Drug Reaction reporting form (25\%) as well as Adverse Drug Reaction reporting system (16\%).

\section{Patient's Practice}

It was found that only $15 \%$ of the sampled patients population had undergone any Adverse Drug Reaction in past while only $5 \%$ had been hospitalized for the Adverse Drug Reaction. Nearly $26 \%$ of the sample had been interacting with the health professionals for possible Adverse Drug Reactions and only $24 \%$ of the sampled patients are aware that the health care professionals are recording the Adverse Drug Reactions in the clinical reports (Table 4). 


\begin{tabular}{|c|c|c|}
\hline \multicolumn{2}{|c|}{ Patient's Knowledge } & \multirow{2}{*}{$\begin{array}{c}\text { Response (\%) } \\
93.9\end{array}$} \\
\hline 101 & Have you heard about side effect in medicines? & \\
\hline 102 & Have you heard about Adverse Drug Reaction in medicines? & 52.4 \\
\hline 103 & Are you aware that_ & 60.3 \\
\hline 111 & $\begin{array}{l}\text { Is side effects and Adverse Drug Reaction should be } \\
\text { reported? }\end{array}$ & 97.3 \\
\hline \multicolumn{2}{|c|}{ Patient's Awareness } & \\
\hline 114 & $\begin{array}{l}\text { Reporting Adverse Drug Reactions improves quality of } \\
\text { patient care }\end{array}$ & 99.4 \\
\hline 115 & $\begin{array}{l}\text { Reporting Adverse Drug Reaction is part of duty of Health } \\
\text { professional }\end{array}$ & 97.3 \\
\hline 116 & $\begin{array}{l}\text { There is a need to confirm that Adverse Drug Reaction is } \\
\text { related to the drug before reporting }\end{array}$ & 90.4 \\
\hline 117 & $\begin{array}{l}\text { Only Adverse Drug Reaction of doctors prescribed drugs } \\
\text { need to be reported? }\end{array}$ & 57.8 \\
\hline 118 & $\begin{array}{l}\text { Adverse Drug Reaction related with non-prescribed drugs } \\
\text { need not to be reported }\end{array}$ & 36.3 \\
\hline 119 & $\begin{array}{l}\text { Only Adverse Drug Reaction that cause persistent disability } \\
\text { should be reported? }\end{array}$ & 62.1 \\
\hline 120 & $\begin{array}{l}\text { Patient should be made aware about Adverse Drug Reaction } \\
\text { reporting }\end{array}$ & 94.9 \\
\hline 121 & One report of Adverse Drug Reaction makes no difference & 38.7 \\
\hline 122 & Reporting is not useful to the patient & 23.8 \\
\hline 123 & $\begin{array}{l}\text { I will report Adverse Drug Reaction, if I encounter such } \\
\text { condition }\end{array}$ & 97.3 \\
\hline 104 & $\begin{array}{l}\text { Do you know Side effects \& Adverse Drug Reactions can be } \\
\text { reported? }\end{array}$ & 36.5 \\
\hline 105 & $\begin{array}{l}\text { Are you aware the availability of side effect and Adverse } \\
\text { Drug Reaction reporting form? }\end{array}$ & 25 \\
\hline 106 & $\begin{array}{l}\text { Are you aware about national side effect and Adverse Drug } \\
\text { Reaction reporting system? }\end{array}$ & 15.9 \\
\hline \multicolumn{2}{|c|}{ Patient's Practice } & \\
\hline 107 & $\begin{array}{l}\text { Have you had any side effects and Adverse Drug Reaction in } \\
\text { past? }\end{array}$ & 15 \\
\hline 108 & $\begin{array}{l}\text { Were you ever hospitalized for any side effects and Adverse } \\
\text { Drug Reaction in past? }\end{array}$ & 5.3 \\
\hline 109 & $\begin{array}{l}\text { Have you told health professional about possibility of } \\
\text { Adverse Drug Reaction \& Side effects in your practice? N= } \\
244\end{array}$ & 25.8 \\
\hline 110 & $\begin{array}{l}\text { Did health care professional record your side effects } \\
\text { \& Adverse Drug Reaction in your clinical reports or } \\
\text { Prescription? N= } 242\end{array}$ & 24 \\
\hline
\end{tabular}

\section{Conclusion}

The project was performed to find the current position of Pharmacovigilance system for Adverse Drug Reaction reporting of the medicines in terms of Knowledge, Attitude \& Practice of the key stake holders in major tertiary care hospitals of Jaipur. It was found that although the health professionals (Doctor, Nurse and Pharmacist) are aware of the basic knowledge about the Adverse Drug Reaction due involvement of key terms in their basic education and training but there is a huge gap found in knowl- edge parameter as seen in unawareness about the reporting system of Pharmacovigilance.

Although it found that the majority of doctors found Adverse Drug Reaction in their daily practices but the awareness found for the Adverse Drug Reaction reporting system is only about in the one third of the doctors and the mandatory time period for the serious Adverse Drug Reaction reporting as well as regional office for Adverse Drug Reaction reporting is known in only about in one fourth of the doctor's sampled population. Such 
a qualified professional people (Doctors) are also confused for where they are going to report about the Adverse Drug Reaction due to the fact that they are neither been provided any training or literature about the Pharmacovigilance and Adverse Drug Reaction procedures (only 6\% are trained) nor there is any defined 'Standard Operating Procedure' for registering \& handling the Adverse Drug Reaction in any hospital, they are been handled as per the individual perceptions, which was found not to be common and varies for every health professional. The given figures for the KAP are relatively poorer in the Nursing and Pharmacist staff.

The patients on the other hand are having less knowledge to the fact related to Adverse Drug Reaction, Pharmacovigilance, their process and their ill hazards then the health professionals. It was found that $15 \%$ of the patient had faced Adverse Drug Reaction while only $5 \%$ had been hospitalized due to this reason. Only one fourth of the patients are proactively for seeking information from health professionals regarding Adverse Drug Reaction.

The common attitude found for all the stakeholders is to reduce the demerits occurring due to adverse effects of the medicines but there is a definite lack of practices found in all the hospitals.

There a difference in encountered Adverse Drug Reaction among government to private sector hospitals in the ratio of 1.3:1.6 i.e. the Adverse Drug Reaction encountered in the private sector is more than the counterpart but the recording of Adverse Drug Reaction is found more in government hospitals in the ratio of 1.7:1.2. Government doctors are also in the practice of usually reporting the Adverse Drug Reaction 1.7 times more than the private sector. While comparing the knowledge of doctors in both hospitals it was found that awareness about the right Adverse Drug Reaction reporting authority is known more in government hospitals to that of private hospitals, in the ratio of 5:3.

It was found that the private sector hospitals are usually advice to your patients on possible drug- drug or drug- food interactions to their patients 4 times more than that of the government hospitals.

In government hospitals there is stronger support $(3.5$ times) by doctors for reporting of all prescribed as well as nonprescribed medicines and also for the disagree (3.2 times) upon the term that only Adverse Drug Reaction that cause persistent disability should be reported than private hospitals. Private hospitals doctors are 4 times surer about the availability of Adverse Drug Reaction reporting forms in their hospitals then govt. hospitals.

The gap thus found in the knowledge as well as practice can be reduced using the techniques of training, assistance, encouragement and involvement of all health centres (Public \& Private), as suggested by majority of stakeholders. Despite being one of the largest nation with huge prevalence of the varied diseases, there is huge problem of under reporting in India (less than 1\% in India compared to $5 \%$ worldwide [12]. The field experience suggested that there is a fear among the stakeholders specially Doctors, for not reporting the Adverse Drug Reaction as it might be correlated with their understanding about the medicine.
The conclusion thus made from the data collected that the Adverse Drug Reaction reporting was found to be low among key stakeholders i.e. Doctors, Pharmacists, Nurses and Patients; there is a huge requirement of providing the training \& awareness for the stakeholders be respective departments as well as by the hospitals as they are not found to be practicing the system as per the applicable standards.

\section{Limitation}

There is problem in getting the approval of the ethical agency of the hospitals, although some of the hospitals denied the application for the ethical approval. The given hurdle is stronger in private hospitals which as less likely to share their working with external agencies and they took more time to get convince about the merits of the project.

The key stakeholders especially doctors are less interested in discussing the key issue of Adverse Drug Reaction and its reporting. The personal if lack any information tries to avoid the survey team or even leave during the survey. Government hospitals having the huge rush during OPD timing made it difficult to reach the key stakeholders and after OPD hours the stakeholders leave the hospitals, so it was difficult to target the stakeholders in Public system.

Patients are found to be less aware to the term 'Adverse drug reaction' hence the common term used to indicate them was 'side effect' as found in the pre testing of the tools.

The current project is limited to the tertiary care hospitals of Jaipur only hence cannot compare it for different cities or geographical region.

The study was conducted as a baseline survey and can be used to assess the current knowledge, attitude and practices of the key stakeholders, it do not involve any use of intervention like training, workshop, campaign etc., hence it is limited to the description of the current status only.

\section{Recommendations}

The current promotional strategy adopted by the 'PvPI' is not able to match the international figures for the Adverse Drug Reaction report by India; we are still facing the problem of under reporting. The recommendation proposed by the findings of the study is to involve the interventions like the awareness campaign, training or involvement of hospitals in the development of Adverse Drug Reaction centres locally.

The study found the low awareness, knowledge as well as practice for spontaneous reporting system adopted for Adverse Drug Reaction reporting in India. It is suggested that the involvement of significance of Adverse Drug Reaction reporting has to be taught in the teaching of the health professionals. The use of continuous medical education or similar training can be beneficiary for strengthening the existing key stakeholders in terms of their knowledge attitude and practices. A system or a vigilance committee has to be generated for the monitoring of the under reporting and its causes in every hospital or region consisting of personals from different hospitals, so to increase the reach as well as collect the problems \& views of the end targets. 
The study found the low KAP for Adverse Drug Reaction reporting as there is less reach of the current system i.e. regional Pharmacovigilance centre, to the key stakeholders and in all hospitals sampled in the study. It is recommended that the local institutional committee can be used for influencing the local key stakeholders so that the effective measures suitable for the need can be targeted and desired output can be achieved.

The Pharmacovigilance program of India can fulfil the target of achieving efficient number of the Adverse Drug Reaction reports unable us to generate efficient signals. The proper and early signal detection can provide more benefit of Indian population in terms of the decision making for the approval \& continuation of safe medicines, inhibition of the irrational combination as per the countries gene pool, food habits and environment.

\section{Ethical Consideration}

Voluntary participation of the key stakeholders and hospitals was included in the study. Privacy confidentiality was maintained for the sake of keeping anonymity and safeguard the right of each respondent; only initials was taken of each respondent instead of the full detail of the stakeholders. Risk involved in the study is the privacy of the organization and its working culture along with key stakeholders. There is no economic benefit involved in the study for the stakeholders.

\section{References}

1. Sengupta A. Universal Health care in India: making it public, making it a reality. Municipal services project. Occasional Paper No. 19. 2013.

2. Edwards IR, Aronson JK. Adverse drug reactions: definitions, diagnosis and management. Lancet. 2000;356(9237):1255-1259.

3. WHO: The safety of Medicines in Public Health Program. WHO Library Cataloguing-in-Publication Data. 2006.
4. Pharmacovigilance Programme of India (PvPI) for Assuring Drug Safety. In: Central Drugs Standard Control Organization. 2015.

5. National Coordination Centre, Pharmacovigilance Programme of India (PVPI). In: Indian Pharmacopoeia Commission. 2014.

6. Wester K, Jönsson AK, Spigset O, Druid H, Hägg S. Incidence of fatal adverse drug reactions: a population based study. Br J Clin Pharmacol. 2008;65(4):573-579.

7. Desai CK, Iyer G, Panchal J, Shah S, Dikshit RK. An evaluation of knowledge, attitude, and practice of adverse drug reaction reporting among prescribers at a tertiary care hospital. Perspect Clin Res. 2011;2(4):129-136. doi: 10.4103/2229-3485.86883

8. Vikas Dhikav, Sindhu Singh, KS Anand. Adverse Drug Reaction Monitoring In India. JIACM 2004; 5(1):27-33.

9. PVPI In: Pharmacovigilance Program of India. 2013.

10. Bahri C. How India Tackles Adverse Drug Reactions-By Ignoring Data. India Spend. 2016.

11. PvPI updates. In: Pharmacovigilance Programme of India- Performance Report. 2015.

12. Akram Ahmad, Muhammad Umair Khan, Jagadeesan Moorthy, Bandari Deepak Kumar, Gogikar Sudhir Kumar, Isha Patel. Comparison of knowledge, attitudes and perceived barriers towards adverse drug reactions reporting between Bachelor of Pharmacy and Doctor of Pharmacy students in Southern India. Journal of Pharmaceutical Health Services Research. 2016; 7(1):63-69. 